\title{
A REGULARIZAÇÃO FUNDIÁRIA POR INTERESSE SOCIAL NA LEI 11.977 DE 07 DE JULHO DE 2009: O EXCESSO PROCEDIMENTAL NA EXIGÊNCIA DA LEGITIMAÇÃO DA POSSE
}

\section{THE AGRARIAN REGULARIZATION FOR SOCIAL INTEREST IN THE LAW 11.977 THE SEVEN OF JULY, 2009: THE EXCESS DEMANDED IN THE LEGITIMACY OF POSSESSION PROCEDURE}

${ }^{1}$ Edimur Ferreira de Faria

${ }^{2}$ Ana Paula Matosinhos

\section{RESUMO}

O objetivo deste artigo é analisar o instituto da regularização fundiária por interesse social previsto na Lei 11.977, de 07 de julho de 2009, como inovador e importante instrumento de política pública urbana na reordenação dos espaços urbanos e consequente inclusão social principalmente da população de baixa renda. Neste estudo serão abordadas as fases, tendo como foco a legitimação de posse. Verificar-se-á se a regularização fundiária por interesse social realmente tem uma relevância na organização dos espaços urbanos e se a legitimação de posse em algumas situações de fato se torna excessiva, prejudicando a efetivação prática da regularização fundiária.

Palavras-chave: Regularização fundiária, Políticas públicas, Legitimação de posse

\begin{abstract}
The purpose of this article is to analyze the institute of agrarian regularization for social interest provided for the Law 11.977/2009, as innovative and important instrument of public policy in the urban reordering of urban spaces and consequent social inclusion mainly the low-income population. This study will be addressed phases, focusing the legitimacy of possession. It shall be verified that the agrarian regularization for social interest actually has a relevance in the organization of urban spaces and if the legitimacy of possession in some situations of fact becomes excessive, impairing the effective practice of agrarian regularization.
\end{abstract}

Keywords: Agrarian regularization, Public policy, Legitimacy of possession

\footnotetext{
${ }^{1}$ Doutor em Direito pela Universidade Federal de Minas Gerais - UFMG, Minas Gerais (Brasil). Professor de Direito pela Pontifícia Universidade Católica de Minas Gerais - PUC, Minas Gerais (Brasil). E-mail: edimur@pop.com.br

${ }^{2}$ Mestre em Direito pela Pontifícia Universidade Católica de Minas Gerais - PUC, Minas Gerais (Brasil).

E-mail: a_matosinhos@hotmail.com
} 


\section{INTRODUÇÃO}

No Brasil contemporâneo, sobretudo a partir da segunda metade do século XX observou-se intenso crescimento urbano informal, gerado pela consolidação de novos assentamentos clandestinos e irregulares, geralmente moradias em favelas ou em loteamentos ilegais periféricos.

Essa urbanização intensa das cidades deveu-se principalmente, à expansão industrial em meados do século passado, gerando desenvolvimento econômico, processo tecnológico, novas formas de organização social e cultural. Esses fatos, entretanto, concorreram para a formação crescente de mão de obra desqualificada, sobretudo, a resultante do êxodo rural, acomodada no subemprego e vivendo em condições quase subumanas, resultante também da má distribuição de renda, fator preponderante para o aumento da pobreza.

Nas lições de Fernandes (2001) o fracasso na redistribuição de renda contribuiu para o aumento da pobreza de significante parcela da população brasileira, inclusive a urbana, elevando, consequentemente, o aumento das desigualdades socioeconômicas, escassez de recursos públicos, principalmente na esfera local, para fins sociais, redução da capacidade institucional e administrativa da ação estatal, crise fiscal e tributária ${ }^{1}$.

Osório (2002) relata que futuro cada vez mais urbano é o que se espera com aumento de $50 \%$ da população mundial nos últimos trinta anos, sendo que deste total, $90 \%$ deverá ocorrer nas áreas urbanas dos países em desenvolvimento.

Essa é a realidade também no Brasil, onde o crescimento econômico resultou numa expansão desordenada das cidades, dando origem à fragmentação e à degradação do espaço urbano.

De acordo com dados do $\mathrm{IBGE}^{2}$, o Brasil possuía até 2010 uma população residente de 190.755.799 de habitantes, dos quais 160.925.804 (84\%) vivem em áreas urbanas; 44 milhões de domicílios urbanos; 6.329 aglomerados subnormais (favelas, invasões, grotas, baixadas, comunidades, vilas, ressacas, mocambos, palafitas); cerca de $28 \%$ das prefeituras declararam a existência de favelas em seus municípios; $46 \%$ das prefeituras declararam a existência de 63 mil loteamentos cadastrados e foram constatados que em 506 municípios

\footnotetext{
${ }^{1} \mathrm{Na}$ década de 80 , a relação entre renda individual dos $5 \%$ mais ricos da população mundial e a dos pobres era da ordem de 1;78; hoje, a mesma relação é da ordem de 1:123. Estima-se que 1,2 bilhões de pessoas vivem na condição de pobreza.

${ }^{2}$ O Censo 2010 compreendeu um levantamento minucioso de todos os domicílios do país. Nos meses de coleta de dados e supervisão, 191 mil recenseadores visitaram 67,6 milhões de domicílios nos 5.565 municípios brasileiros para colher informações sobre quem somos, quanto somos, onde estamos e como vivemos.
} 
existem algum tipo de programa de regularização fundiária, de favelas ou loteamento irregulares.

Em 2012, foi lançado em todo o mundo, o relatório inédito 'Estado das Cidades da América Latina e Caribe', produzido pelo Programa das Nações Unidas para os Assentamentos Humanos (ONU-HABITAT),no Relatório sobre cidades Latino-americanas organizado pela ONU, vinte anos após a Cúpula da Terra, no Rio de Janeiro,constatou-se que a consciência da América Latina e do Caribe sobre os problemas do meio urbano era maior do que no passado, mas a adoção de medidas ambiciosas em escala local ainda é incipiente, embora as cidades estejam assumindo papel mais importante no plano internacional. Fortalecer a coordenação entre entidades de um mesmo governo, entre os níveis de governo e com os setores privados e da sociedade civil é uma condição para alcançar resultados à altura do dinamismo econômico da região ${ }^{3}$.

Nesse mesmo relatório, ainda se observou que nos últimos anos tem se observado aumento na atividade normativa para a revisão das leis relacionadas ao ordenamento territorial e à gestão da cidade, algo que parece indicar interesse político renovado nessas questões.

No Brasil, já vigorava normativamente uma série de instrumentos de política urbana em consonância com a Constituição brasileira, que desde 1988 consolidou a importância da gestão urbana como forma de desenvolvimento econômico e social. O Estatuto da Cidade, Lei $\mathrm{n}^{\mathrm{o}}$ 10.257, de 10 de julho de 2001 também funciona como importante programador de instrumentos jurídicos para a promoção de programas de regularização fundiária dos assentamentos informais, promovendo formas de acesso ao solo urbano e moradia.

Fernandes (2002), analisando, naquela época o recente Estatuto da Cidade, lições que ainda permanecem atuais, afirmou que a Lei $\mathrm{n}^{\circ}$ 10.257/2001 confirma e amplia o espaço constitucional garantido para a ação dos municípios no controle do processo de desenvolvimento urbano, regulamentando instrumentos urbanísticos que podem não apenas promover a regulação normativa dos processos de uso, desenvolvimento e ocupação do solo urbano, mas especialmente induzir ativamente os rumos de tais processos.

Com o Estatuto da Cidade, os gestores públicos passaram a contar com uma série de instrumentos urbanísticos e foi nessa seara, objetivando dar mais eficiência à regularização

\footnotetext{
${ }^{3}$ Em 1946, a Assembleia Geral criou os Centros de Informação das Nações Unidas, conhecidos pela sua sigla em inglês, UNICs, que têm como missão principal divulgar as atividades da Organização. O UNIC Rio foi o primeiro centro a abrir suas portas na América Latina e funciona, desde 1947, na cidade do Rio de Janeiro.
} 
fundiária que no ano de 2009 foi editada a Lei $n^{\circ} 11.977$, de 7 de julho de $2009^{4}$, que dentre outras medidas, criou a regularização fundiária de interesse social, um instituto originariamente brasileiro, que combinou instrumentos já existentes no ordenamento jurídico brasileiro, como a demarcação urbanística, a legitimação de posse e a usucapião, mas com uma interligação jamais vista em leis anteriores, como a usucapião administrativa, por exemplo. O referido instituto é um dos meios jurídico-administrativos mais modernos e atuais entre os disponíveis para a implementação da política organizacional do solo, com vistas a impulsionar o cumprimento e efetivação da função social da propriedade em busca da efetivação da dignidade da pessoa humana relacionada à moradia.

\begin{abstract}
Rodrigues (2012) ressalta que: A partir da edição da Lei 11.977/2009, é possível a aquisição da propriedade imobiliária (com a formação do respectivo título), em razão da posse prolongada, através da usucapião administrativa, depois de realizado o processo de regularização fundiária. A regularização fundiária de interesse social foi o instituto jurídico mais inovador e revolucionário até então criado como instrumento de regularização imobiliária no país. Consistiu em profunda mudança política no modo tradicional de administração urbanística das cidades brasileiras que, num passado recente, consistia na remoção (ou expulsão) dessas populações para a periferia das grandes cidades, passando a adotar um modelo que busca fixar essas populações no local em que se deu a ocupação (artigo publicado www.conjur.com.br)
\end{abstract}

A regularização fundiária por interesses social tem por objetivo não só auxiliar a gestão pública na solução dos problemas urbanísticos, ambientais e sociais em virtude da desorganização do parcelamento do solo dos municípios brasileiros, mas também o de proporcionar à população a sua inclusão social, consubstanciando o acesso ao direito à propriedade privada, com todos os seus efeitos, principalmente o direito ao registro da propriedade nos competentes cartórios de registros imobiliários considerando que, tradicionalmente, no ordenamento jurídico brasileiro, a prova de aquisição da propriedade de imóveis é constituída de maneira formal, com a apresentação do título hábil ao serviço de Registro de Imóveis competente.

É nesse contexto, que este trabalho tem por tema central analisar o procedimento adotado pela Lei $\mathrm{n}^{\circ} 11.977 / 2009$ para efetivar a regularização por interesse social promovida

\footnotetext{
${ }^{4}$ Dando complementariedade à legislação preexistente, tais como as leis $\mathrm{n}^{\mathrm{o}} 10.257 / 2001$ (Estatuto da Cidade), lei $\mathrm{n}^{\circ}$ 11.481/2007 (Demarcação de terras públicas devolutas para regularização fundiária de interesse social pertencentes à União, Estado, ao Distrito Federal e Territórios) e lei no 11.888/2008, foi editada a lei 11.977/09, e dentre vários institutos fez surgir a regularização fundiária por interesse social.
} 
pelos órgãos da Administração Pública, abordando suas etapas e os institutos jurídicos que as compõem no desenvolvimento do programa, abordando principalmente, o instituto da legitimação de posse e sua conversão em usucapião.

Diante desse panorama, o presente artigo busca responder as seguintes indagações: a) a regularização fundiária por interesse social prevista na Lei $n^{\circ} 11.977 / 2009$ contribui efetivamente para a organização da política urbana e inclusão social? b) em relação ao seu procedimento, seria a legitimação de posse necessária em todos os casos de regularização fundiária de interesse social promovida pelo Poder Público? c) em caso de sua supressão, o procedimento seria mais eficaz, contribuindo para mais rápida formalização da propriedade nos serviços registrais?

Assim, objetiva-se ressaltar a importância da regularização por interesse social no processo de diminuição das desigualdades sociais quando a mesma alcança o direito de propriedade privada, principalmente à população de baixa renda; ressaltar que a regularização é espécie de política pública fundamental para o desenvolvimento fático do direito urbanístico nas cidades; e demonstrar que principalmente que o procedimento de regularização fundiária por interesse social pode ser simplificado, com a supressão, em alguns casos, do termo de legitimação de posse, sem interferir na essência do instituto.

A finalidade precípua desta pesquisa é contribuir para que o instituto da regularização fundiária por interesse social promovida pelo Poder Público, seja um instrumento eficiente e eficaz na realização da política de reordenação do solo, de garantia para a efetivação do direito a uma moradia digna e maior inclusão social da população de baixa renda.

Nesta pesquisa a metodologia utilizada terá abordagem qualitativa, trazendo novas informações sobre a regularização fundiária, preocupando-se com aspectos da realidade. Quanto à natureza, a pesquisa será aplicada, objetivando gerar conhecimentos para a aplicação prática da regularização fundiária de interesse social. A pesquisa terá objetivos exploratórios e descritivos, valendo-se de levantamento bibliográfico, análise de pesquisas já concebidas por diversos órgãos e institutos especializados, como o IBGE e a ONU. E, ainda, exame da legislação pertinente. 


\section{DA REGULARIZAÇÃO FUNDIÁRIA POR INTERESSE SOCIAL NA LEI 11.977/09 E SEU PROCEDIMENTO ADMINISTRATIVO}

A Constituição da República de 1988 dispensa atenção à realidade das cidades brasileiras, dispondo de normas com o objetivo de estabelecer programas governamentais que contribua para a minimização dos problemas urbanísticos. Assim, estabelece nos artigos 182 e 183, que a política de desenvolvimento urbano tem por objetivo ordenar o pleno desenvolvimento das funções sociais das cidades e garantir o bem-estar dos habitantes pátrios e, também, instituiu a usucapião especial urbana para fins de moradia.

Em sintonia com a Constituição, conforme ressalta ALFONSIN (2006), o Estatuto da Cidade, cujo projeto foi protocolizado em 1990, levou mais de uma década para ser aprovado, passando a viger somente em 2001.

O Estatuto foi forjado, frisa-se, dentro de um quadro urbano de profunda exclusão socioterritorial, com grande defasagem temporal face ao crescente déficit habitacional e do acirramento dos problemas atinentes à ordenação urbana, com insuficientes instrumentos de regularização fundiária e, ainda, ressentindo-se de mecanismos capazes de frear a produção irregular de nossas cidades (ALFONSIN, 2006, p. 283-286).

Conforme ressalta Melo (2008),

O Estatuto da Cidade, dentre as diversas diretrizes gerais que apresenta, estabelece o direito à moradia (inciso $\mathrm{I}$ do artigo $2^{\circ}$ ), a regularização fundiária e a urbanização de áreas ocupadas por população de baixa renda mediante o estabelecimento de normas especiais de urbanização, uso e ocupação do solo e edificação, consideradas a situação socioeconômica da população e as normas ambientais (inciso XIV do artigo $2^{\circ}$ ) como metas políticas a serem atingidas .

(MELO, 2008, p. 123).

Para o mesmo autor o direito urbanístico anterior ao Estatuto da Cidade conduzia a uma dissensão entre a cidade formal e a cidade informal, na medida em que gerava incompatibilidade insanável entre as ocupações populares e a ordem urbanística ideal, ao passo que o Estatuto da Cidade aponta para nova direção, de modo que a legislação deve servir não para impor um ideal idílico de urbanismo, mas para construí-lo a partir dos dados da vida real.

Entretanto, o Estatuto da Cidade não foi suficiente para efetivar a regularização fundiária em todas as cidades brasileiras. A incompletude do Estatuto da Cidade ensejou a 
edição da Lei $\mathrm{n}^{\circ}$ 11.977/2009, que dispõe sobre mecanismos de incentivo à produção e à aquisição de novas unidades habitacionais ou requalificação de imóveis urbanos e produção ou reforma de habitações rurais, e cria mecanismos originais de regularização fundiária de assentamentos localizados em áreas urbanas.

Como ressalta ALFONSIN (2006):

A nova lei busca frear a ocupação irregular de nossas cidades, atentando, dessa forma, aos riscos de que a regularização fundiária, como intervenção protagonista da política habitacional, acabe atuando como cúmplice da irregularidade ao reforçar, no imaginário popular, que sempre haverá regularização e, portanto, não há problema em ocupar irregularmente.

( ALFONSIN, 2006, p. 285).

A regularização fundiária é o processo que inclui medidas jurídicas, urbanísticas, ambientais e sociais, com a finalidade de integrar assentamentos irregulares ao contexto legal das cidades, garantindo o direito social à moradia e o cumprimento da função social da propriedade, considerando a assentamentos irregulares, as ocupações inseridas em parcelamentos informais ou irregulares, localizados em áreas urbanas públicas ou privadas, predominantemente utilizadas para fins de moradia.

De acordo com o art. 47, incisos VII e VIII da Lei nº 11.977/2009, a Regularização Fundiária pode ser de duas espécies: a) de interesse social: regularização de assentamentos irregulares ocupados, predominantemente, por população de baixa renda, nos casos: em que tenham sido preenchidos os requisitos para usucapião ou concessão de uso especial para fins de moradia; de imóveis situados em ZEIS ${ }^{5}$; ou de áreas da União, dos Estados, do Distrito Federal e dos Municípios declaradas de interesse para implantação de projetos de regularização fundiária de interesse social; b) regularização fundiária de interesse específico: regularização fundiária na qual não está caracterizado o interesse social nos termos acima ${ }^{6}$

Além das diretrizes da política urbana constante do plano diretor de cada cidade, nos termos estabelecidos pelo Estatuto da Cidade, a regularização fundiária deverá observar os

\footnotetext{
${ }^{5}$ A ZEIS é um Instrumento previsto pelo Estatuto da Cidade que permite a delimitação e destinação de determinadas áreas do Município para abrigar moradia popular, com o objetivo de implantar habitação de interesse social. É uma maneira de assegurar terras bem localizadas e providas de infraestrutura para o uso da população de baixa renda, criando uma "reserva de mercado" para habitação social. A delimitação de ZEIS é definida no Plano Diretor do Município ou em lei municipal específica. Além disso, as ZEIS determinam normas especiais de uso, ocupação, parcelamento do solo e edificação para áreas já ocupadas por assentamentos informais. Essas normas são específicas para a área que será objeto de regularização, esteja ela vazia ou ocupada.

${ }^{6}$ A modalidade interesse específico atrai natureza residual, relaciona-se á regularização fundiária das demais hipóteses, isto é, poderá ser utilizada para regularizar qualquer assentamento urbano que não se enquadre na classificação de interesse social. O procedimento em qualquer das duas categorias resulta, genericamente, em dois efeitos em favor da regularização fundiária: uma maior mitigação de algumas exigências urbanísticas e ambientais e a aplicabilidade da usucapião extrajudicial. In: Carla Fernandes de Olivera. Usucucapião administrativa. Editora Ágora 21 Multifoco. Rio de Janeiro. p. 152. 2015.
} 
seguintes princípios: a) ampliação do acesso à terra urbanizada pela população de baixa renda;b) interação com políticas setoriais de habitação, meio ambiente, saneamento básico e de mobilidade urbana, em ação conjunta do governo e a sociedade; c) estímulo à resolução extrajudicial de conflitos e d) concessão do título preferencialmente para a mulher.

Já o inciso VII do art. 47 da mesma lei estabelece alguns requisitos para a regularização fundiária de interesse social:

a) que a área esteja ocupada, de forma mansa e pacífica, há, pelo menos, 5 (cinco) anos; (Redação dada pela Lei $n^{\circ} 12.424$, de 2011)

b) de imóveis situados em ZEIS; ou

c) de áreas da União, dos Estados, do Distrito Federal e dos Municípios declaradas de interesse para implantação de projetos de regularização fundiária de interesse social. Neste último caso, reforça-se a ideia de que se a regularização fundiária por interesse social ocorrer em áreas da União, Distrito Federal e dos Municípios, portanto, bens públicos, mesmo anuindo à regularização pleiteada, não haverá posterior ato de legitimação de posse e posterior conversão em propriedade particular, tendo-se em vista a vedação constitucional de prescritibilidade de bens públicos. Portanto, quando houver a constatação de regularização em área pública, outros instrumentos poderão ser formalizados, entre as quais a concessão de uso especial para fins de moradia ${ }^{7}$.

O procedimento de regularização fundiária de interesse social, promovida pelo Poder Público em terrenos particulares materializa-se observadas as quatro etapas seguintes: Demarcação urbanística; Projeto de regularização; Legitimação de posse; Usucapião administrativa, conversão do registro de legitimação de posse em propriedade pela usucapião administrativa.

\subsection{A DEMARCAÇÃO URBANÍSTICA}

Como ressalta LAMANA PAIVA (2014), a demarcação urbanística caracteriza-se como espécie de procedimento administrativo utilizado pelo Poder Público quando empreende a realização da Regularização Fundiária de Interesse Social, envolvendo o Registro de Imóveis e dispensando a atuação do Poder Judiciário. Materializa-se por meio da lavratura do auto de demarcação, previsto no art. 56 da Lei n. 11.977/2009, pelo órgão

\footnotetext{
${ }^{7}$ A concessão de uso especial pra fins de moradia é um instrumento que regulariza a posse em face de bens públicos, prevista na Medida Provisória nº 2.220/2001.
} 
promovente da regularização, com base no levantamento da situação da área a ser regularizada e na caracterização da ocupação (grifo nosso).

Trata-se, portanto, de um ato administrativo procedimental pelo qual o Poder Público demarca imóvel de domínio público ou privado, definindo seus limites, área, localização e confrontantes, com a finalidade de identificar seus ocupantes e qualificar a natureza e o tempo das respectivas posses.

Aludido instrumento aplica-se exclusivamente na regularização fundiária de interesse social, em áreas consolidadas, ocupadas por população de baixa renda, onde não haja oposição do proprietário do imóvel.

A demarcação urbanística somente pode ser feita pelo Poder Público, União, Estados, Municípios e Distrito Federal, incluindo as entidades da Administração Pública indireta investidas dessa atribuição. Em se tratando de competência da Administração Pública, nos casos de terras particulares, qualquer um desses entes é legitimado a promovê-la. Nos casos de áreas públicas, qualquer ente pode fazer a demarcação de terras de seu próprio domínio. Entretanto, podemos verificar que entre os entes federais, estaduais ou distritais, há uma certa hierarquia administrativa ${ }^{8}$.

Como dito, apesar do procedimento da regularização fundiária não ser procedimento exclusivo dos órgãos da Administração Púbica, se for iniciado pelo Poder Público, somente seus órgãos têm competência legal para realizá-lo.

O auto de infração, por ser instrumento primordial no estabelecimento da regularização fundiária, deve ser obrigatório, a despeito de o art. 56 da lei em foco prescrever que o Município poderá lavrar o auto de infração.

Neste sentido aduz OLIVEIRA (2015) :

Se o referido auto constitui um título hábil para ser levado á matrícula do imóvel, eis que sem este não há possibilidade de continuidade do procedimento de regularização fundiária por interesse social, não se trata de mera opção do Poder Municipal, mas sim de verdadeiro dever. ( OLIVEIRA, 2015, p. 162).

O auto de demarcação conterá os seguintes documentos: a) planta e memorial descritivo da área a ser regularizada, nos quais constem suas medidas perimetrais, área total, confrontantes, coordenadas preferencialmente georreferenciadas dos vértices definidores de

\footnotetext{
8 A demarcação em terras federais, em razão da Seção III-A do Decreto-Lei no 9.760/46, somente poderá ser feita pela própria União. Já a demarcação em terras municipais compete também aos Estados e à União. Já em áreas estaduais, compete ao próprio Estado e à União.
} 
seus limites, número das matrículas ou transcrições atingidas, indicação dos proprietários identificados e ocorrência de situações mencionadas no inciso I do $\S 6^{\circ}$; b) planta de sobreposição do imóvel demarcado com a situação da área constante do registro de imóveis e, quando possível, com a identificação das situações mencionadas no inciso I do $\S 6^{\circ}$; e c) certidão da matrícula ou transcrição da área a ser regularizada, emitida pelo registro de imóveis, ou, diante de sua inexistência, das circunscrições imobiliárias anteriormente competentes.

Também devem integrar esse auto as cópias das notificações e respectivas respostas enviadas aos órgãos de administração patrimonial dos demais entes federados (União, Estados, Distrito Federal e Municípios) para que se manifestassem no prazo de 30 dias, de acordo com a previsão do $\S 2^{\circ}$ do art. 56 da Lei n. 1.977/2009.

O órgão do Poder Público promovente da regularização deverá, em seguida, remeter o ato comprobatório de demarcação urbanística por ele realizada, ao Registro de Imóveis competente, com pedido de averbação, conforme dispõe o art. 57 da Lei n. 11.977/2009.

No Cartório de Registro de Imóveis, o documento deve ser protocolado, para em seguida dar início às buscas destinadas a identificar o proprietário da área a ser regularizada e as matrículas ou transcrições que a tenham por objeto.

Realizadas as buscas e identificados os proprietários das áreas abrangidas pelo auto de demarcação, o oficial do Registro de Imóveis deverá notificá-los, assim como aos confrontantes, pessoalmente, por via postal com aviso de recebimento (AR), ou por meio do Registro de Títulos e Documentos da comarca de situação do imóvel ou de domicílio dos notificando-os para que estes apresentem impugnação ao pedido, no prazo de 15 dias.

De acordo com o $\S 4^{\circ}$ do art. 57, se os prazos fixados decorrerem sem que ocorra apresentação de impugnação, ou superada essa fase dentro dos moldes legais, a demarcação urbanística será averbada na matrícula alcançada pela planta e memorial descritivo. Caso ainda não exista matrícula, a mesma será aberta para posterior averbação.:

Salles (2009) afirma que :

Não é exigido do município grande rigor no cumprimento deste item, pois o perfeito enquadramento da área regularizanda aos padrões registrais foi atribuído ao Oficial de Registro de Imóveis. As dúvidas ou incertezas quanto ao mais próprio enquadramento não poderão obstar a expedição do auto de demarcação. Voltamos aqui a ressaltar o sentido da função social da propriedade, que inverte as prioridades, prestigiando o interesse coletivo em contrapartida com o individual (SALLES, 2009, pág. 5). 
Finalizada essa etapa, iniciarão os trabalhos para realizar o projeto de regularização. Portanto, ao observar o auto de demarcação teremos duas certezas: a identificação daquele que detém a posse ou propriedade e a delimitação individualizada de cada área ou lote.

Portanto, o projeto de regularização, de competência do Poder Público tem o condão, não mais de tratar de assuntos de posse e propriedade, nem de fixar as áreas individuais, públicas ou privadas. Seu condão é o de organizar a regularização individual com as demais normas urbanísticas, previstas em leis federais, estaduais e municipais, buscando consonância procedimental com eventuais leis de parcelamento do solo, plano diretor, e demais atos normativos urbanísticos.

\subsection{O PROJETO DE REGULARIZAÇÃO}

Nesse ponto, as diretrizes de direito urbanístico serão fundamentais para se formular o projeto de regularização fundiária de interesse social, pois tal projeto será elaborado pelo Poder Público com a participação da sociedade, e deverão ser observados nesse processo o uso e desenvolvimento do solo, criando direitos e obrigações, tanto para os agentes privados quanto públicos. Posteriormente será aprovado pelo Município e deverá ser executado, momento este em que ocorrem as transformações no ambiente: abertura de vias, realocação de moradias, eliminação de riscos, realização de obras de infraestrutura e instalação de equipamentos urbanos.

Como ressalta Oliveira (2015), o projeto a ser elaborado pelo titular ativo deverá atender a pressupostos que guardam estreita ligação com o procedimento de loteamento, previsto na Lei $n^{\circ}$ 6.766/79. Se um dos objetivos incide na regularização do parcelamento do solo e formalização, permitindo o nascedouro das matrículas individualizadas de cada unidade habitacional, se faz necessário que se defina as áreas a serem regularizadas, as vias de circulação existentes ou projetadas, as medidas necessárias à sustentabilidade urbanística, social e ambiental, a promoção da segurança da população e as medidas de infraestrutura básica.

O projeto deve ser aprovado pelo Município, pois determina a realização do parcelamento de solo urbano, previsto para a gleba demarcada, no âmbito territorial do Município no qual se processa a regularização fundiária. O parcelamento decorrente da execução do projeto deve ser, a seguir, submetido a registro, em obediência ao que dispõe o caput do art. 58 da Lei n. 11.977/2009. Esse ato de registro de parcelamento será lançado na matrícula geral aberta para a gleba demarcada. 
Para o completo registro de parcelamento originado da execução do projeto de regularização há necessidade, também, de abertura concomitante de matrículas para todas as parcelas decorrentes do projeto, visto que as áreas já estão totalmente identificadas e localizadas, sejam elas destinadas aos lotes, ao sistema viário ou às áreas públicas, nelas lançando-se o respectivo ato de registro de parcelamento.

Nesse sentido SALLES ( 2009) ressalta:

O novo projeto determinará o descerramento de nova matrícula considerando o fracionamento do solo, indicando a área total, cada um dos lotes e as áreas públicas (art. 66.I), gerando segurança jurídica ao permitir melhor exame registral, afastando as incertezas determinadas pela imperfeição descritiva das antigas glebas. (SALLES, 2009, pag.09).

O próximo passo será estabelecer o título individualizado de legitimação de posse.

\subsection{LEGITIMAÇÃO DE POSSE}

A distribuição de terras no Brasil se deu sob a égide do Brasil- Colônia, pelo regime sesmarial nos moldes do tradicional direito de Portugal, que vigorou até 7 de julho de 1822 . Após essa data, conforme salienta TORMINN (1974) vigorou no Brasil o chamado "regime de posses" sistema segundo o qual a aquisição de tratos ou dadas de terra se dava por intermédio de uma posse que proporcionasse povoamento e utilização econômica do bem, não havia uma distinção clara entre posse e propriedade. Com a edição da Lei $n^{\circ} 601$, de 18 de setembro de 1850 , denominada Lei da Terra ${ }^{9}$, foram criados os institutos: terra devoluta e legitimação de posse, sendo esta meio de aquisição de propriedade.

\section{Nas licões de Borges:}

A Lei de Terras promove a primeira "Regularização Fundiária" de que se tem notícia em nossa história, sendo certo que esta consiste precisamente no processo pelo qual busca-se trazer aquele que se encontra em situação precária, instável, anormal e irregular em sua relação com a terra de que se utiliza, para o mundo da certeza, previsibilidade e estabilidade do ordenamento jurídico, o que se processará por meio de sua titulação como proprietário - ou, na pior das hipóteses,

como detentor de um direito real, portanto, derivado da propriedade. Tal perspectiva

\footnotetext{
${ }^{9}$ Seguindo orientação legal do Decreto-lei n. ${ }^{0} 9.760$, de 1946, e do Decreto-lei n. ${ }^{\circ} 1.164$, de 1971 , entende-se por terras devolutas aquelas que não se encontram aplicadas a algum uso público, nem estejam incorporadas ao domínio particular, as situadas nas faixas de fronteiras, nos territórios federais, no Distrito Federal, e as declaradas indispensáveis à segurança nacional. Art. $5^{\circ}$. "Serão legitimadas as posses mansas e pacíficas adquiridas por ocupação primária, ou havidas de primeiro ocupante, que se acharem cultivadas ou com princípio de culturas, e moradia habitual do respectivo posseiro, ou de quem o represente, guardadas as regras seguintes..."
} 
veio a determinar os contornos jurídicos do instituto da posse civil no direito brasileiro, a qual, quando distanciada da propriedade, será sempre representada como situação de incompletude e precariedade, não possuindo qualquer valor intrínseco, exceção única na hipótese de aquisição - o que não destoa da lógica do sistema, visto que esta significará o ingresso do possuidor no mundo dos proprietários. ( BORGES, Paulo Torminn. Institutos básicos do direito agrário. São Paulo, Juriscredi, 1974)

Conforme afirma MELO (2008), com o Estatuto da Terra- Lei Federal no 4.504 de 30 de novembro de 1964 foi estabelecida a legitimação de posse como forma de aquisição da propriedade imobiliária em terras devolutas federais ${ }^{10}$.

Nessa evolução histórica, a legitimação de posse ainda foi prevista na Constituição da República de 1967, por meio da Emenda no 01/1969 no artigo 171: “ a lei federal disporá sobre as condições de legitimação de posse e de preferência para aquisição, até 100 hectares, de terras públicas, por aqueles que as tornarem produtivas com seu trabalho e o de sua família”. A Lei $\mathrm{n}^{\circ}$ 6.383, de 07 de dezembro de 1976 disciplinou com novas regras legitimação de posse.

BARROSO E PASSOS (2004) asseveram que diante desse diploma jurídico, a legitimação de posse tomou novos contornos, consistindo em ato administrativo que deve ser precedido de outro, a licença de ocupação, que só será obtida se atendidos pelo possuidor os seguintes requisitos prévios: a) serem as terras devolutas; b) área de até 100 (cem) hectares; c) comprovação de morada permanente e cultura efetiva, pelo lapso temporal não inferior a 1 (um) ano; d) não ser proprietário de imóvel rural; e) exploração de atividade agrária com seu trabalho e o de sua família direta e pessoalmente. Após 4 anos com o título de legitimação, o interessado terá preferência para a aquisição do lote, pelo valor da terra nua, satisfeitos os requisitos de moradia permanente e cultura efetiva comprovada a sua capacidade para desenvolver a área ocupada.

Assim, o título de legitimação de posse era título precário que só materializava o fato da posse, em relação ao titular do domínio útil, pois não alterava a situação dominial dos imóveis demarcados.

\footnotetext{
${ }^{10}$ Os artigos 99 e 100 da lei $n^{\circ} 4.504 / 64$ previa que a transferência do domínio ao posseiro de terras devolutas federais efetivar-se-á no competente processo administrativo de legitimação de posse, cujos atos e termos obedecerão às normas do Regulamento da presente lei. Este título, que será expedido pelo Instituto Brasileiro de Reforma Agrária será,dentro do prazo estabelecido pelo Regulamento, transcrito no Registro Geral de Imóveis.
} 
MELO (2008) aduz que a Lei $n^{\circ}$ 6.368/76 representa retrocesso em relação ao Estatuto da Terra, pois o detentor da legitimação de posse somente será proprietário se pagar por ela e após concessão de licença de ocupação.

Outros diplomas foram surgindo, como a Medida Provisória $\mathrm{n}^{\circ}$ 2.220/01 que estabeleceu a legitimação de posse em imóveis privados urbanos, mas com caráter possessório. Lei $\mathrm{n}^{\circ} 11.481 / 07$, que prevê a legitimação de posse em imóveis da União. A lei $n^{\circ}$ 11.952/09 que instituiu a legitimação de posse na Amazônia legal.

E foi com essa essência, de regularizar a posse e não de outorgar diretamente a propriedade, que a legitimação de posse foi prevista na Lei $\mathrm{n}^{\circ} 11.977 / 09$. Posteriormente à averbação do auto de demarcação urbanística e do registro do parcelamento do solo, o Poder Público promovente da regularização concede, aos ocupantes cadastrados, o competente título de legitimação de posse que, depois de registrado, confere, em favor do detentor da posse direta sobre o imóvel parcelado, o direito a posse titulada.

A legitimação de posse é reconhecida aos moradores nos termos do parágrafo único do art. 59 da Lei n. 11.977/2009 desde que não sejam concessionários, foreiros ou proprietários de outro imóvel urbano ou rural e que não sejam beneficiários de legitimação de posse concedida anteriormente.

É a partir do registro do título de legitimação que inicia a contagem do prazo de posse ad usucapionem a ser integralizado pelo possuidor. Decorrido prescricional aquisitivo, devidamente reconhecido, o posseiro poderá converter o seu título de posse em título dominial. Somente com essa conversão ocorrerá a materialização do direito de propriedade. Portanto, a legitimação de posse é título que protege a posse, mas não constitui aquisição de propriedade.

\subsection{A CONVERSÃO DA LEGITIMAÇÃO DE POSSE EM USUCAPIÃO}

Um dos maiores avanços normativos da Lei $\mathrm{n}^{\circ}$ 11.977/09 refere-se à desjudicialização da usucapião para fins de moradia. Ao contrário da exigência que se fazia no Estatuto da Cidade, da indispensabilidade de ação judicial, a inovadora lei prescreve que o procedimento da regularização fundiária por interesse social seja extrajudicial e legitimou o Oficial de Registro de Imóveis competente do reconhecimento da usucapião. Não se trata de facultatividade, o procedimento corre nos serviços registrais, onde já foram registrados a demarcação urbanística, o projeto de regularização, o título de legitimação de posse, e por fim, a usucapião para fins de moradia. 
O momento final do processo de regularização fundiária de interesse social é marcado pela conversão do título de posse em título de propriedade, que deverá ser requerido pelo detentor do título ao oficial de registro de imóveis.

No requerimento de conversão, serão exigidos, além dos 5 anos de registro da legitimação da posse, certidões negativas de ações reipersecutórias sobre o bem, declaração de que não possui outro imóvel urbano ou rural e que o o imóvel é utilizado para sua moradia ou de sua família; além de não ter reconhecido anteriormente o direito à usucapião de imóveis em áreas urbanas.

Ocorre que, para que haja a conversão, nos termos do art. $60, \S 3^{\circ}$, da lei em comento, o detentor do título de legitimação de posse registrado deverá aguardar o prazo específico previsto legalmente nas hipóteses possíveis de usucapião que será de 5 ou de $10 \operatorname{anos}^{11}$ para ter direito à usucapião.

Nesse ponto, estar-se-á diante de algumas situações, entre elas:

a) aquele que já é proprietário e tem seu registro não precisará de título de legitimação de posse, caso em que se necessário, apenas deverá ser adequada a sua nova matrícula;

b) aquele que tem justo título, mas por razões impeditivas no ordenamento jurídico, não pode ingressar anteriormente no registro de imóveis;

c) aquele que somente é possuidor de área privada, mas que está desprovido de título;

Ocorre que nos dois últimos casos, que na prática deverão ser os mais corriqueiros a lei impõe espera desnecessária, postergando efeitos que poderiam ser constituídos de imediato. Refere-se à espera por um prazo que já foi cumprido pelo interessado, qual seja o de 5 anos, pois como requisito legal para a implementação da regularização fundiária, é mister que a ocupação irregular seja de no mínimo, 5 anos. Ora, se já se comprovaram 5 anos de posse mansa e pacífica, que são as exigência para o reconhecimento da usucapião especial, por quê se exigir mais 5 anos, previstos na Lei ${ }^{\circ} 11.977 / 2009$ ?

Ao fazer a demarcação urbanística, ao se registrar o projeto e o parcelamento, já houve a identificação do ocupante, titulado ou não, tanto que as matrículas já foram abertas

\footnotetext{
${ }^{11}$ Essa modalidade inicialmente limitava a extensão dos lotes a $250 \mathrm{~m}^{2}$, porém desde a edição da Lei $12.424 / 2011$, é permitida também em relação a lotes com extensão maior do que $250 \mathrm{~m}^{2}$, devendo observar, entretanto, os prazos da usucapião ordinária e extraordinária previstos, respectivamente, no parágrafo único do artigo 1.242 (5 anos) e no parágrafo único do artigo 1.238 (10 anos), ambos do Código Civil, hipóteses legais fundadas em moradia. Assim, o artigo 60, caput e $\S$ 3ำ, da Lei 11.977/2009 permite que o possuidor do título de legitimação de posse, após cinco ou dez anos do respectivo registro, requeira ao oficial do Registro de Imóveis a conversão do título de legitimação em título de propriedade do imóvel regularizado.
} 
individualmente. Para que essas providências se efetivassem, foi necessária comprovação temporal de, no mínimo 5 (cinco) anos ou até mesmo de no mínimo 10 ( dez anos) necessários para a usucapião ordinária.

É nesse viés, que se observa que o instituto da legitimação de posse se torna completamente desnecessário no procedimento, dificultando ainda mais a efetividade da regularização fundiária, veja-se:

a) pressupostos objetivos: na fase da demarcação urbanística, já foram amplamente discutidos e comprovados documentalmente todos os assuntos referentes à identificação da área a ser regularizada. Também já foram delimitadas e individualizadas as áreas privadas e públicas.

b) pressupostos subjetivos: sob esse aspecto também já conhecem os sujeitos que serão beneficiados na regularização. Sua identificação já foi analisada tanto pelo Poder Público competente, quanto pelo oficial de registro de imóveis. Se o auto de demarcação foi averbado, pelo menos, na seara administrativa, não mais será objeto de discussão.

Seria agora, mais eficiente se o oficial de registro de imóveis, ao verificar toda a documentação individualizada de cada interessado, pudesse instaurar o procedimento administrativo de usucapião, independentemente de anterior registro de ato legitimação de posse, e ao constatar o preenchimento dos requisitos para a espécie correta de usucapião, que requeresse ao Poder Público termo de usucapião, ou se ele mesmo, pudesse findar o procedimento com a declaração de usucapião por ato de ofício.

Mello (2008), antes mesmo da vigência da Lei 11.977/09 já identificava a importância da titulação de propriedade, não só como mecanismo de regularização, mas de solidariedade:

Por conseguinte, objetiva-se que seja outorgado o qualificado direito de propriedade para todos aqueles que, sem a intervenção estatal, seriam mantidos afastados deste direito real, porque é só assim, através da atribuição da titularidade dominial formal a cada um e a todos indistintamente, com vistas à inclusão dos menos favorecidos (economicamente vulneráveis) e com idêntica intensidade jurídica, que se consumará a idealizada igualdade, que tem por fundamento a dignidade da pessoa humana. Isto se perfaz, no caso da regularização fundiária urbana, com a inclusão dos membros das classes sociais historicamente excluídas do processo formal de apropriação da terra (que teve, e continua a ter por regra a compra e venda levada a registro no cartório competente, como principal instrumento de aquisição), para somente a partir daí se ter reconhecida a verdadeira propriedade imobiliária (MELO, 2008, p. 56). 
A legitimação de posse passaria a ter cabimento na hipótese do ocupante ainda ter que perfazer prazo para completar os 10 (dez) anos de posse para os casos de usucapião ordinária prevista no art. 1.242 do Código Civil e extraordinária, pro moradia, previsto no art. 1.238 do mesmo diploma.

Além disso, esse entendimento se coadunaria ainda mais com a previsão contida no Código de Processo Civil Brasileiro que entrou em vigor no dia 18 de março de 2016, criando e estabelecendo diretrizes normativas para a usucapião extrajudicial no corrente processo de desjudicialização de conflitos.

\section{CONCLUSÃO}

No contexto atual, o direito urbanístico conta com uma série de instrumentos de regularização fundiária que dinamiza política pública de reordenação do solo urbano, de adequação das ocupações irregulares ao direito de propriedade plena e digna moradia, contribuindo assim para a diminuição das desigualdades econômicas e sociais da população urbana.

Com esse objetivo, a Lei $\mathrm{n}^{\circ} 11.977 / 09$ concebeu um prático procedimento de regularização fundiária de assentamos irregulares ou ilegais no espaço urbano, denominado de - REGULARIZAÇÃO FUNDIÁRIA POR INTERESSE SOCIAL- esse procedimento esbarra em alguns dificultadores: de ordem econômica, o seu alto custo; de ordem social, a falta de conhecimento jurídico dos aplicadores em relação ao procedimento legal; de ordem política, os interesses diretos dos governantes e de ordem jurídica, o procedimento legal.

Evidenciou-se que, todas as etapas do procedimento administrativo da regularização fundiária por interesse social culminam em um ponto primordial: outorgar ao ocupante da área demarcada o título de propriedade, pois de nada adiantaria o esforço do legislador, o empenho do Poder Público e das demais entidades autorizadas a promover a regularização se ao final, ficasse frustrada a aquisição de propriedade pelo ocupante. Por isso, a Lei $\mathrm{n}^{\circ}$ 11.977/2009 disciplina, com clareza, as etapas do procedimento, com a participação do Poder Público, da sociedade e dos oficiais de registro de imóvel. Estabelece, ainda, ligação entre os institutos jurídicos da demarcação urbanística, projeto de regularização, legitimação de posse e usucapião.

Mas, foi preocupação de esgotar o assunto e não deixar a margem de dúvidas, omissões, interpretações que pudessem comprometer a celeridade do procedimento é que 
parece ter havido excessos. Alguns procedimentos arrolados poderiam ser simplificados, ou até mesmo suprimidos em determinadas situações.

Foi nesse contex to que se identificou que pelo fato da lei já exigir como requisito básico para o início do procedimento que a ocupação da área irregular ocorrida há pelo menos 5 (cinco ) anos, aquele que já tiver essa comprovação, exaustivamente analisada pelo Poder Público e pelo oficial de registro de imóveis, deveria de pronto ser contemplado com os títulos de propriedade, sem a necessidade de prévio título de legitimação de posse.

Por fim, chegou-se à conclusão que a legitimação de posse e seus contornos previstos na Lei 11.977/09 não se coadunam com a necessidade de uma política pública eficiente na regularização fundiária por interesse social, dificultando o projeto de reordenação do solo, de desenvolvimento e inclusão social, de sustentabilidade e de aquisição de propriedade plena.

Essa análise crítica que se objetiva fazer neste artigo tem o intuito de contribuir para que a regularização fundiária se torne mais atrativa para a sociedade, dando mais estímulos para que a mesma cobre do Poder Público a sua implementação e que esse mesmo estímulo possa nascer e se desenvolver na Administração Pública, porque não há nada mais desmotivador do que a burocracia desnecessária.

\section{REFERÊNCIAS}

ALFONSIN, Betânia de Moraes. O significado do estatuto da cidade para os processos de regularização fundiária no Brasil.

Betânia de Moraes. Da usucapião especial de imóvel urbano. In: MATTOS, Liana Portilho (Org.). Estatuto da Cidade Comentado. Belo Horizonte. Editora Mandamentos,2002.

ALMEIDA, Roberto Moreira de Almeida. Sesmarias e terras devolutas. Revista de Informações legislativas. Volume 40, n. 158, p. 310. Abril a junho de 2013.

BARROSO, Lucas Abreu. Passos, Lisita Cristiane. Direito Agrário Contemporâneo. Belo Horizonte. Del Rey, 2004.

BORGES, Paulo Torminn. Institutos básicos do direito agrário. São Paulo, Juriscredi, 1974.

BRASIL. Constituição (1988). Constituição da República Federativa do Brasil. Brasília: Senado Federal, 1988.

BRASIL. Lei $\mathrm{n}^{\circ} 10.257$ de 10 de julho de 2001. Disponível em http://www.planalto.gov.br. Acesso: 01 de março de 2015. 
BRASIL. Lei $\mathrm{n}^{\circ} 11.977$ de 07 de julho de 2009. Disponível em http://www.planalto.gov.br. Acesso: 01 de março de 2015.

BRASIL. Ministério das Cidades. Regularização Fundiária Urbana: Como aplicar a Lei Federal no 11.977/2009. Brasília. Ministério das Cidades, Secretaria Nacional de Habitação e Secretaria Nacional de Programas Urbanos, 2010.

FERNANDES, Edésio. Cidade, memoria e legislação. Org:Jurema Rugani), Belo Horizonte: $\mathrm{IAB}, 2002$.

Del Rey,2001.

Edésio. Direito Urbanístico e Politica Urbana no Brasil, (org) Belo Horizonte:

IBGE. Censo Demográfico 2010 Tabela: Domicílios particulares ocupados e população residente em domicílios particulares ocupados, total e em aglomerados subnormais, e número de aglomerados subnormais, segundo as Grandes Regiões, as Unidades da Federação e os municípios.Disponível:www.ibge.gov.br/home/estatistica/populacao/censo2010/aglomerados _subnormais/aglomerados_subnormais_tab_pdf.shtm>. Acessado em 03 de março de 2016.

LIMA, Ruy Cirne. Pequena história territorial do Brasil: sesmarias e terras devolutas. Porto Alegre: Sulina, 1954.p.11

MELO, Marcelo Augusto Santana de. O direito à moradia e o papel do registrado de imóveis na regularização fundiária. In: Revista de Direito Imobiliário, n. 69, ano 33, São Paulo: Revista dos Tribunais, julho-dezembro de 2010.

MELO, Marco Aurélio Bezerra de. Legitimação de posse dos imóveis urbanos e o direito à moradia. Rio de Janeiro: Lumen Juris, 2008.

MEUCCI, Simone. História do Brasil: Sociedade e Cultura. Série Aspectos da História do Brasil. Curitiba. Ibpex.,2011

OLIVEIRA, Carla Fernandes de. Usucapião Administrativo. Editora Àgora. Multifoco,2015.

ONU-HABITAT. Relatório sobre cidades latino-americanas. Estado das Cidades Latinoamericanas e Caribe. Disponível em: www.onuhabitat.com. Acesso em: 28 de fevereiro de 2016.

OSÓRIO, Letícia Marques (Org.). Estatuto da Cidade e Reforma Urbana: Novas Perspectivas para as Cidades Brasileiras. Sérgio Antônio Fabris Editor. Porto Alegre. 2002.

PAIVA , João Pedro Lamana. A regularização fundiária de acordo com a Lei 11.977/2009. Caderno $\mathrm{n}^{\circ} 5$ do IRIB. Instituto dos Registradores de Imóveis do Brasil. São Paulo. IRIB. 2012.

PINTO, Victor Carvalho. Direito Urbanístico: Plano Diretor e Direito de Propriedade. 3. ed. São Paulo: Revista dos Tribunais, 2011. 
ROGRIGUES, Marcelo. Regularização fundiária de interesse social é imperativo. 2012. Disponível em: www.conjur.com.br/regularizacaofundiariadeinteressesocialeimperativo. Revista Consultor Jurídico . Data: 30 de outubro de 2012.Acessado em 04 de março de 2016.

SALLES, Venício. Usucapião Administrativa- Lei 11.977/2009. Artigo disponível em http://registradores.org.br/usucapiao-administrativa-lei-11.977/2009. Acesso em 11 de março de 2016.

SILVA. Jose Afonso da. Direito urbanístico brasileiro. 3 ed. rev. e atual. São Paulo: Malheiros Editores, 1995. p 37.

VENOSA. Sílvio de Salvo. Direitos Reais. Coleção Direito Civil. Vol.4. São Paulo. 2012. 